Revista Grifos - Unochapecó

\title{
ANÁLISE DA COMPOSIÇÃo E DISTRIBUIÇÃO DAS RECEITAS DE ESTABELECIMENTOS FAMILIARES NA REGIÃO NORDESTE
}

\author{
ANALYSIS OF THE COMPOSITION AND DISTRIBUTION OF REVENUES FROM FAMILY OWNED \\ IN THE NORTHEAST REGION (BRAZIL)
}

\section{ANÁLISIS DE LA COMPOSICIÓN Y DISTRIBUCIÓN DE INGRESOS DE ESTABLECIMIENTOS FAMILIARES EN LA REGIÓN NORDESTE (BRASIL)}

\author{
Adrielli Santos de Santana ${ }^{1}$ \\ https://orcid.org/0000-0003-2001-4488 \\ Gesmar Rosa dos Santos ${ }^{2}$ \\ https://orcid.org/0000-0002-7897-138X
}

Submissão: 30/11/2021 / Aceito: 02/03/2021 / Publicado: 31/03/2021.

\begin{abstract}
Resumo
Este artigo tem como objetivo caracterizar a composição das receitas e rendas de estabelecimentos agropecuários que integram o modelo familiar e identificar a presença de padrões de comportamento espacial entre as receitas e seus componentes na região Nordeste do Brasil. Para tanto, foram realizadas análises descritivas de dados do Censo Agropecuário 2017 e uma abordagem espacial através do cálculo do Índice I de Moran, para medir a presença de autocorrelação espacial, e análise de clusters, para verificar o comportamento das receitas na região. Os resultados apontam para heterogeneidades entre os modelos familiar e não familiar na região e indicam uma grande dependência do produtor familiar a fontes externas de rendas, a exemplo das aposentadorias e pensões. Apesar da fraca autocorrelação espacial, os clusters das receitas externas e rendas provenientes de políticas e programas governamentais se sobrepõem à área abrangida pelo semiárido, indicando maior dependência desses recursos nesses municípios.
\end{abstract}

Palavras-chave: Agricultura Familiar. Análise Espacial. Nordeste. Receita. Semiárido.

\begin{abstract}
This article aims to characterize the composition of the revenues and income of agricultural establishments that integrate the family model and to identify the presence of patterns of spatial behavior between the recipes and their components in the Northeast region of Brazil. To this end, descriptive analyzes of data from The Census of Agriculture 2017 and a spatial approach were performed through the calculation of Moran's Index, to measure the presence of spatial autocorrelation, and cluster analysis, to verify the behavior of recipes in the region. The results point to heterogeneities between the family and non-family models in the region and indicate a great dependence of the family producer on external sources of income, such as retirements and pensions. Despite the weak spatial autocorrelation, the clusters of external revenues and income from government programs overlap the area covered by the semiarid,

\footnotetext{
${ }^{1}$ Doutoranda em Economia pela Universidade de Brasília (UnB). Pesquisadora do Programa de Pesquisa para o Desenvolvimento Nacional (PNPD) na Dirur/Ipea.. E-mail: adrielli_santana@outlook.com

2 Doutor em Desenvolvimento Sustentável pelo Centro de Desenvolvimento Sustentável da Universidade de Brasília (UnB). Técnico de planejamento e pesquisa da Diretoria de Estudos e Políticas Regionais, Urbanas e Ambientais (Dirur) do Ipea - Brasília (DF), Brasil . E-mail: gesmar.santos@ipea.gov.br
} 
indicating a greater dependence on resources from policies and programs in these municipalities.

Keywords: Family farming. Spatial Analysis. Brazilian Northeast. Revenue. Semiarid.

\section{Resumen}

Este artículo tiene como objetivo caracterizar la composición de los ingresos de los establecimientos agrícolas que integran el modelo familiar e identificar la presencia de patrones de comportamiento espacial entre los ingresos y sus componentes en la región Nordeste de Brasil. Para ello, se realizaron análisis descriptivos de los datos del Censo Agropecuario 2017 y un enfoque espacial mediante el cálculo del Índice I de Moran, para medir la presencia de autocorrelación espacial, y análisis de conglomerados, para verificar el comportamiento de los ingresos en la región. Los resultados apuntan a heterogeneidades entre los modelos familiares y no familiares en la región e indican una gran dependencia del productor familiar de fuentes externas de ingresos, como jubilaciones y pensiones. A pesar de la débil autocorrelación espacial, los conglomerados de ingresos externos e ingresos de políticas y programas gubernamentales se superponen con el área cubierta por el semiárido, lo que indica una mayor dependencia de estos recursos en estos municipios.

Palabras chave: Agricultura familiar. Análisis espacial. Nordeste brasileño. Ingresos. Semi árido.

\section{INTRODUÇÃO}

A popularização do termo "agricultura familiar", intensificado na década de 1990, e posteriormente com a publicação da Lei $\mathrm{n}^{\circ}$ 11.326/2006, motivou um grande número de estudos voltados a entender o comportamento do modelo familiar de produção agropecuária. No Brasil, tais estudos abordaram não somente questões econômicas, como também sociais e ambientais, com destaque para as análises de políticas públicas, uma vez que, a partir do ano de 2006, foi crescente o número de políticas e programas que tiveram agricultores familiares e a produção familiar como público-alvo.

A visibilidade dada à agricultura familiar nesse período foi motivada, principalmente, pelas lutas por reconhecimento dos pequenos e médio proprietários rurais, assentados da reforma agrária, ribeirinhos e comunidades tradicionais (FRANÇA; GROSSI; MARQUES, 2009). No debate que se seguiu foi estruturada a classificação das propriedades agropecuárias em familiares e não familiares, a partir dos dados do Censo Agropecuário de 2006 realizado pelo Instituto Brasileiro de Geografia e Estatística (IBGE, 2009), sendo esta a principal pesquisa sobre o meio rural no país. A partir de então, as análises sobre a agricultura familiar no Brasil ganharam subsídios quantitativos e qualitativos, fomentando políticas públicas.

Com a divulgação dos dados do Censo Agropecuário 2017, ressurge um grande interesse sobre o comportamento da agricultura familiar e as transformações desse modelo 
de produção ao longo dos dez anos que separam o atual e o último levantamento. Mudanças na legislação, entretanto, indicam a necessidade de se aprimorar os procedimentos de análise, embora não tenham retirado as questões de fundo sobre o conceito de agricultura familiar. Os dados revelam que ocorreu uma diminuição de $11 \%$ no número de propriedades rurais familiares no país, e um aumento de $1 \%$ na área ocupada por esses estabelecimentos. $\mathrm{O}$ valor da produção agropecuária familiar ultrapassa $\mathrm{R} \$ 106,4$ bilhões, o que sugere um incremento próximo a 5\%, em termos reais, em relação a 2006. Ainda assim, essa produção representa apenas $23 \%$ da produção brasileira, sendo o restante proveniente de propriedades não familiares (IBGE, 2020). Além disso, mais de 50\% dos estabelecimentos familiares estão localizados na região Nordeste, o que torna essa região de interesse para o estudo. Cabe destacar que uma das justificativas para a variação no número de estabelecimentos está associada às mudanças metodológicas e aos novos critérios de classificação da agricultura familiar, utilizados pelo IBGE (DEL GROSSI, 2019; DEL GROSSI; FLORIDO; RODRIGUES, 2019).

A região Nordeste possui uma agropecuária bastante diversificada, em toda a extensão do seu território. Todavia, a prática agropecuária possui grandes desafios, muitos dos quais não são observados em outras regiões do país. Castro (2012) analisa as principais limitações para o desenvolvimento da agricultura no Nordeste, sendo possível identificar os seguintes aspectos: (i) grande parte do território nordestino encontra-se na região Semiárida, sendo a ocorrência de secas um desafios para a manutenção das atividades produtivas, agravadas pela escassez hídrica e pela uso inadequado de práticas para conter a erosão do solo; (ii) a perda de competitividade nacional, associada principalmente ao altos custos de transporte das mercadorias agrícolas; e (iii) limitação tecnológica, de infraestrutura, de assistência técnica e o limitado acesso do produtor a sistemas de crédito, afetando fatores com a produtividade e os rendimentos agrícolas. Embora tais problemas sejam comuns aos estabelecimentos agropecuários nordestinos, os efeitos sobre os estabelecimentos familiares apresentam uma maior magnitude, sendo mais afetados pelos problemas ambientais, pela forte concorrência dos produtores não familiares, pela limitação tecnológica e de escala de produção. Essas características dificultam também o acesso ao crédito e a seguros.

Diante desse contexto, o presente estudo visa ampliar o debate sobre a agricultura familiar no Nordeste, tendo como principal foco a análise das receitas e rendas dos estabelecimentos familiares, a partir dos dados declaratórios do Censo Agropecuário 2017. 
A escolha por analisar a composição das receitas desses estabelecimentos justifica-se por ser um importante critério para caracterizar a estrutura financeira da agricultura familiar. Além disso, adicionando as contribuições fornecidas pelo uso de ferramentas de análise espacial, é possível identificar e ilustrar padrões de comportamento das receitas e rendas, demonstrando as heterogeneidades presentes nos estabelecimentos familiares dentro da região.

Além deste texto introdutório, o artigo é estruturado em mais quatro seções. A segunda seção apresenta uma revisão de literatura sobre a agricultura familiar no Brasil e na região Nordeste, elucidando aspectos conceituais e apontando os principais desafios desse sistema. Na terceira seção são descritos os procedimentos metodológicos utilizados nas análises, juntamente com as fontes dos dados utilizados. A quarta seção dedica-se a apresentar os resultados obtidos nesta pesquisa. Por fim, a última seção apresenta as considerações finais.

\section{BREVES CONSIDERAÇÕES SOBRE A AGRICULTURA FAMILIAR NO BRASIL E NO NORDESTE}

O sistema de produção familiar foi responsável pelo desenvolvimento de atividades agropecuárias desde o século XVI, coincidindo com o início da colonização brasileira (NETTO, 2008). Entretanto, o reconhecimento da agricultura de pequeno porte e familiar nas políticas públicas de maior peso no país é datado na década de 1990 e ganhou destaque nas agendas políticas e sociais devido a três principais fatores: (i) a onda de movimentos sindicais que surgiram após o fim da ditadura militar, em 1985; (ii) o crescente debate realizado por pesquisadores, especialistas e pela academia, muitos influenciados pelas discussões internacionais, visto que anterior a isso, a temática da agricultura familiar no Brasil era pouco difundida; e (iii) inserção da agricultura familiar nas agendas de políticas públicas, com destaque para a criação do Programa Nacional de Fortalecimento da Agricultura Familiar (PRONAF), através do Decreto n ${ }^{\circ}$ 1.946, de 28 de junho de 1996 (SCHNEIDER; CASSOL, 2013; PICOLOTTO, 2014).

Entretanto, apesar dos avanços legais obtidos após a promulgação da Constituição de 1988, a sequência de dois governos liberais, nos mandatos presidenciais de 1992 a 2002 (governos Collor de Mello e Henrique Cardoso), uma sequência de ações reduziu expectativas e realidades de avanços nas políticas públicas. Esse período foi marcado por ampliação de heterogeneidades (BELIK, 2015) e por retrocessos na questão agrária e de 
produção agrícola tais como: i) estagnação da destinação de terras para a reforma agrária, diante do tamanho do déficit social nesta área; ii) desestruturação das políticas de crédito, seguros, armazenamento e formação de estoques; iii) desestruturação dos serviços de assistência técnica rural (Ater) e de instituições ligadas ao tema; iv) fim ou extrema redução dos subsídios aos produtores de pequeno porte, inclusive para instalação de sedes no meio rural nos poucos assentamentos criados; v) apoio à concentração de terras, capital e tecnologia com o apoio às políticas de exportação de commodities, levando inclusive ao aumento da concentração da terra e renda no meio rural; vi) apoio irrestrito à importação de sementes e pacote tecnológico incluindo insumos industriais com fertilizantes e agrotóxicos.

O uso intensivo de energia externa aos estabelecimentos (CAPORAL; COSTABEBER, 2004) completa o cenário de práticas que afetam o meio ambiente e dificultam a agroecologia. O incentivo à escala e à industrialização de produtos veio, no mesmo sentido, concentrar as formas de contratos na integração produtiva, o que posteriormente se estende ao cooperativismo (MEDEIROS, 2006), fazendo com que o agricultor familiar seja menos sujeito no seu estabelecimento, na sua forma de reprodução.

Esse conjunto de ações, principalmente a retirada do Estado no apoio à pequena agricultura, simbolizada pela extinção, em 1992, governo Collor de Melo, da Empresa Brasileira de Assistência Técnica (Embrater), a falta de ativos (financeiros, de recursos naturais e tecnológicos) afetou fortemente os agricultores familiares. Particularmente, a região Nordeste, por intercalar períodos de estiagem de difícil produção (SANTANA E SANTOS, 2020; LIMA, 2020), sofreu mais ainda com essa agenda liberal.

Sistemas produtivos alternativos à agenda liberal têm enfrentado enormes dificuldades, mesmo após a criação de políticas mais voltadas para a agricultura familiar e sustentabilidade socioambiental, no contexto do Programa Nacional da Agricultura Familiar, nos anos 2003-2014. Como retratado em Caporal e Costabeber (2004), Sambuichi et al. (2017), a agenda concentradora de ativos produtivos, da renda e da riqueza no campo avolumaram as dificuldades de estruturação, difusão, organização produtiva e inserção de produtos agroecológicos no mercado.

Netto (2008) destaca as dificuldades para a obtenção de um consenso para conceituar o termo "agricultura familiar", visto que as abordagens mais simplistas referiam-se àquelas cuja propriedade dos meios de produção e, inclusive, todo o trabalho empregado nas 
atividades produtivas eram desempenhados pela família. Por outro lado, os sistemas familiares divergiam entre as regiões e países, e consequentemente os interesses, valores, as capacidades e as formas de obtenção dos meios de produção entre os produtores rurais eram heterogêneas, demonstrando que tal conceito deveria levar em consideração as diversidades, ou particularidades, observadas em cada contexto (NETTO, 2008).

No Brasil, a definição de agricultura familiar tem como principal definição o texto publicado na Lei $\mathrm{n}^{\mathrm{o}} 11.326$, de 24 de julho de 2006, que estabeleceu as diretrizes para as políticas públicas destinadas a agricultura familiar e empreendimentos familiar. Sabourin (2017, p. 282) argumenta que antes da institucionalização da agricultura familiar como uma categoria política, os produtores familiares representavam uma "categoria social histórica". Deste modo, o autor destaca a importância de revisar e atualizar o conceito de agricultura familiar apresentado no texto da Lei $n^{\circ} 11.326 / 2006$, e baseado no Decreto ${ }^{\circ} 1.946 / 1995$, que institui o Pronaf, visto que a legislação não acompanha as transformações socioeconômicas do meio rural.

Quase onze ano após a publicação da Lei da Agricultura Familiar, novas mudanças para o entendimento da agricultura familiar no Brasil são apresentadas no Decreto $\mathrm{n}^{\circ}$ 9.064, de 31 de maio de 2017. A contribuição desta publicação consiste na introdução do termo Unidade Familiar de Produção Agrária (UFPA), além de apresentar as definições de empreendimento familiar rural, empresa familiar rural, cooperativa singular e cooperativa central da agricultura familiar e associação da agricultura familiar (BRASIL, 2017). Por meio desse decreto fica instituído que a UFPA e o empreendimento familiar, além de atender o critério de área máxima de quatro módulos fiscais, devem empregar no mínimo de 50\% da mão de obra familiar na produção e na geração da renda, auferir, no mínimo, metade da renda proveniente de atividades econômicas realizadas no próprio estabelecimento e o estabelecimento ou empreendimento deve apresentar uma gestão predominantemente familiar (BRASIL, 2017).

Del Grossi (2019) apresenta que, ainda no ano de 2017, surge um conjunto de portarias e regulamentações que delimitam ainda mais os conceitos de agricultura e empreendimentos familiares. O autor destaca a Portaria SAF/SEAD n 001 que reforça o limite de área do estabelecimento familiar, bem como o uso da força de trabalho, local de residência do produtor e os limites de renda familiar adotados para a emissão da Declaração de Aptidão ao Pronaf (DAP). Maiores detalhamentos também foram realizados pelo 
Conselho Monetário Nacional (CMN), no Manual de Crédito Rural, para definir os grupos beneficiários do Pronaf (MCR-10- 2-1 e MCR 10-2-2) (DEL GROSSI, 2019).

De acordo com Baiardi e Alencar (2014), a agricultura familiar difere de empreendimentos familiares. Essa diferença é sustentada pelo argumento de que os agricultores familiares não possuem a mesma percepção de mercado necessária a esses empreendimentos, ou seja, eles são menos vulneráveis às estabilidades de mercado e às dinâmicas econômicas e financeiras, visto que a opção por continuar desenvolvendo atividades produtivas está mais relacionada às questões "afetivas e culturais" do que aos fatores puramente econômicos. Complementando esta análise, Schneider e Cassol (2017) demonstram que muitos agricultores familiares contemporâneos mantêm suas origens camponesas, mas ao mesmo tempo apresentam características de empreendimentos econômicos. No entanto, ao contrário da limitada interação social restrita a pequenas comunidades rural característica dos sistemas campesinos, a atual agricultura familiar apresenta maior interação com o meio urbano, com os mercados, para além das fronteiras da propriedade familiar (SCHNEIDER; CASSOL, 2017).

Cabe destaque, que mesmo após os avanços na institucionalização da agricultura familiar e a inclusão dessa categoria nas agendas de políticas públicas, muito dos problemas enfrentados pelos agricultores em outrora permanecem atuais, como destacado no trecho a seguir:

\footnotetext{
A pobreza, a privação de renda e a vulnerabilidade social continuam a afetar muitos destes produtores e suas famílias, da mesma forma como no passado. Por isto, é importante enfatizar que a mudança de nome ou a adoção de nova terminologia, por si, não altera a condição real de vida dos agricultores familiares e menos ainda a sua identidade (SCHNEIDER; CASSOL, 2017, p. 86).
}

Baiardi e Alencar (2014), ao analisar a resiliência da agricultura familiar no Brasil, contrapõem os problemas enfrentados por dois grupos de produtores familiares. No primeiro grupo destacam-se os estabelecimentos que exercem o sistema de produção familiar, mas possuem melhores condições para garantir seu desenvolvimento, por exemplo, através de melhores garantias para demandar crédito ao mercado, acesso a recursos e conhecimentos, e outro importante fator destacado pelos autores é a localização em áreas geográficas que minimizam os riscos às atividades produtivas. Por outro lado, o segundo grupo é composto por produtores familiares em condições de vulnerabilidade socioeconômica, cujas atividades produtivas desenvolvem em ambientes com adversidades ambientais. Como exemplo, os 
autores destacam os produtores familiares localizados em regiões semiáridas, que compõem um grupo representativo dos produtores rurais no Brasil, salientando que este grupo carece de maior atenção por parte das esferas públicas, de forma a criar condições e perspectivas para garantir sua sobrevivência e dar oportunidades para o seu desenvolvimento (BAIARDI; ALENCAR, 2014).

A partir desse exemplo, é possível verificar uma grande quantidade de estudos que se propuseram a analisar a agricultura familiar no Nordeste, e mais precisamente na porção semiárida. Freire (1999) analisou a trajetória das políticas públicas da década de 1990 e seus impactos na promoção do desenvolvimento produtivo e sustentável da agricultura familiar no semiárido. Como resultado, o autor destaca que as políticas não foram efetivas, uma vez que a agricultura familiar nessa porção do Nordeste não tinha condições de concorrer com a abertura comercial e com os sistemas patronais, além disso muitos dos estabelecimentos familiares foram enquadrados como "periféricos" pelas regras do Pronaf, ficando marginalizados de quaisquer outras políticas públicas.

Além dos problemas socioeconômicos e ambientais característicos da agricultura familiar no Nordeste, Castro (2015), ao estabelecer uma relação entre a importância da assistência técnica para a agricultura no Brasil e nesta região, destaca que o baixo nível de escolaridade e de capacitação média dos agricultores é um dos desafios enfrentados por esse segmento, que historicamente é marginalizado do acesso a serviços de ATER. Em consequência desse cenário, o autor destaca ainda que:

\footnotetext{
Essa baixa qualificação da mão de obra se refletiu na não adoção de tecnologias, na não utilização de cuidados culturais ou no uso de práticas incorretas no processo produtivo, perdas na produção e baixos rendimentos na medida em que os agricultores se veem impossibilitados de adotar inovações tecnológicas disponíveis (CASTRO, 2015, p. 54).
}

Fazendo uma análise comparativa dos avanços da agricultura familiar no Nordeste, através dos levantamentos do Censo Agropecuário de 1995/96 e de 2006, Guanziroli, Di Sabbato e Vidal (2014) identificaram avanços voltados ao uso eficientes dos fatores de produção, mas com baixa evolução no uso de tecnologias e de assistência técnica. Além disso, o estudo identificou heterogeneidades na agricultura familiar na região, constatando a presença de agricultores familiares altamente produtivos e responsáveis pela "concentração da renda monetária líquida" (p. 104), em oposição a sistemas familiares de baixa 
produtividade e, consequentemente, em processo de estagnação. Esse contexto reafirma a importância de investigar a concentração e a geração de renda nos estabelecimentos familiares do Nordeste.

\section{PROCEDIMENTOS METODOLÓGICOS}

A espacialização e a concentração das receitas provenientes de estabelecimentos familiares na região Nordeste serão abordada por meio de duas análises distintas. Primeiramente, será realizada uma análise descritiva dos dados do Censo Agropecuário 2017, a fim de captar as diferenças no comportamento e na composição das receitas em estabelecimentos familiares e não familiares na região. A segunda análise consiste no cálculo do índice I de Moran, como ferramenta para a identificação de padrões de comportamento espacial para cada grupo de receitas.

\section{Análise exploratória de dados espaciais}

O estudo é baseado na hipótese de dependência espacial das receitas provenientes de estabelecimentos agropecuários familiares no Nordeste; ou seja, assume-se que os valores das receitas em associação a uma determinada localização geográfica possuem maior tendência a apresentar resultados mais semelhantes ao valores de seus municípios vizinhos do que com outras localizações que compõem a totalidade da região. Isso se aplica, no caso da agricultura, principalmente sendo os ativos produtivos e os estabelecimentos comparáveis (pelo tamanho, tipo de terra, acesso a água, à assistência técnica e políticas públicas comuns), tanto por proximidades de infraestruturas quanto em relação aos riscos. Para testar tal hipótese, foi realizada uma análise exploratória de dados, utilizando o cálculo do coeficiente de correlação espacial I de Moran, que quantifica o grau dessa associação espacial.

Inicialmente, foi construída uma matriz de pesos espaciais, considerando os municípios vizinhos de primeiro grau, ou seja que possuem fronteiras físicas em comum, atribuindo valor unitário para municípios vizinhos e valor nulo, caso contrário. Em seguida, calcula-se o I de Moran global, proposto por Anselin (1995), e expresso pela seguinte equação, apresentada por Câmara et al. (2004): 


$$
I=\frac{\sum_{i=1}^{n} \sum_{j=1}^{n}\left(z_{i}-\bar{z}\right)\left(z_{j}-\bar{z}\right)}{\sum_{i=1}^{n}\left(z_{i}-\bar{z}\right)^{2}}
$$

onde: $n$ é o número de observações; $z_{i}$ e $z_{j}$ são os valores da variável de interesse (com média $\bar{Z}$ ) para as unidades espaciais $i$ e $j$; e $w_{i j}$ é o peso espacial para o par de unidades $i$ e $j$, medindo o grau de interação entre elas.

As estimativas do I de Moran têm valores esperados iguais a $\{-[1 /(n-1)]\}$. Assim, valores acima e abaixo desse valor esperado indicam a ocorrências de autocorrelações positivas e negativas, respectivamente.

Além do Índice de I de Moran Global, Anselin (1995) propôs um Índice de Moran Local, que mensura a existência de dependências ou de autocorrelações espaciais em níveis locais, ou em microescalas. Este índice pertence a um grupo de índices denominados por Indicadores Locais de Associação Espacial (LISA, do inglês Local Indicators of Spatial Association), que possibilitam a decomposição de indicadores globais de autocorrelação espacial, a exemplo do Índice de Moran Global, considerando a contribuição unidades individuais (ANSELIN, 1995).

As estimativas do I de Moran Local para análises univariada e multivariada são obtidas por meio da Equação (2) (LUZARDO; CASTAÑEDA FILHO; RUBIM, 2017).

$$
I_{i}=\frac{\left(z_{i}-\bar{y}\right) \sum w_{i j}\left(z_{j}-\bar{z}\right)}{\sum_{i}\left(z_{i}-\bar{z}\right)^{2} / n}
$$

A principal diferença entre o índice de Moran Global e o índice de Moran Local, consistem em o primeiro medir a autocorrelação de primeira ordem entre os valores observados em uma localidade e nas localidades vizinhas, enquanto o segundo produz padrões locais de dependência espacial, definindo valores específicos para cada localidade. Além disso, o índice local possibilita a identificação de agrupamentos que apresentam valores semelhantes das variáveis selecionadas, chamados de clusters espaciais, e valores discrepantes, denominados outliers espaciais. A representação dos clusters e outliers espaciais dão origem aos mapas LISA (LISA maps). 


\section{Fonte dos dados}

Visando analisar o comportamento das receitas de estabelecimentos rurais, classificados como agricultura familiar, o presente trabalho considera dados para os 1.793 municípios que compõem a região Nordeste, extraídos do levantamento do Censo Agropecuário 2017, disponibilizados pelo IBGE em sua plataforma SIDRA (Sistema IBGE de Recuperação Automática).

Foram consideradas as informações declaratórias das receitas por municípios, estados e por grupos de área total. As receitas são classificadas em três grupos: (i) receitas de produção do estabelecimento (RPROD); (ii) outras receitas dos estabelecimentos agropecuários (REST); e (iii) outras receitas do produtor rural, que correspondem às rendas externas (REXT). Dentro do grupo de outras receitas, considerou-se a soma das rendas provenientes de políticas e programas governamentais (federais, estaduais e municipais), a esta nova categoria foi dado o nome de rendas de programas governamentais (RGOV).

\section{RESULTADOS E DISCUSSÕES}

De acordo com dados do Censo Agropecuário 2017, existem 2.322.719 estabelecimentos rurais na região Nordeste, dos quais $1.838 .846(79,17 \%)$ são enquadrados no modelo de agricultura familiar (IBGE, 2020), cabendo destaque para o fato de mais de $32,8 \%$ dos estabelecimentos agropecuários estarem situados no estado da Bahia, que também apresenta o maior percentual de estabelecimentos familiares $(32,2 \%)$.

Todavia, apesar da representatividade do modelo familiar em termos de quantidade de estabelecimentos, o mesmo não ocorre em termos de valor da produção. O levantamento do Censo estima um valor superior a $\mathrm{R} \$ 37,6$ bilhões decorrentes da produção não familiar, contrapondo $\mathrm{R}$ \$ 15,8 bilhões da agricultura familiar. Em média, calcula-se que cada estabelecimento não familiar gera um valor de $\mathrm{R} \$ 77.859,25$, enquanto os estabelecimentos familiares geram um valor médio de $\mathrm{R} \$ 8.635,30$, resultando em uma diferença nove vezes menor.

A produção vegetal representa $60,5 \%$ do valor total, ou pouco mais de $\mathrm{R} \$ 32,6$ bilhões, dos quais R $\$ 24,9$ bilhões (77\%) são originados em estabelecimentos não familiares (IBGE, 2020). A produção animal, com pouco mais de $\mathrm{R} \$ 21,1$ bilhões, apresenta pouca 
discrepância entre estes dois modelos, sendo 60,3\% desse valor provenientes de estabelecimentos não familiares e 39,7\% provenientes de estabelecimentos familiares (IBGE, 2020).

No Brasil cerca de $40 \%$ dos estabelecimentos agropecuários têm como finalidade principal da produção o consumo próprio, sendo $69 \%$ dos declarantes localizados na região Nordeste. Dentro do modelo de agricultura familiar $62 \%$ declararam produção para autoconsumo, contrapondo $56 \%$ dos estabelecimentos não familiares da região. Mais de $80 \%$ dos estabelecimentos situados nos estados do Piauí e Ceará e em municípios da região semiárida possuem produção voltada principalmente para subsistência. O excedente da produção, quando não consumido, é destinado à comercialização, no entanto em apenas $21 \%$ desses estabelecimentos regionais os produtores apontaram que as rendas das atividades desenvolvidas no estabelecimento superam as outras receitas do produtor; $24 \%$ para a agricultura familiar e 14\% para não familiar.

Um fator que merece destaque é a composição das receitas dos estabelecimentos agropecuários do Nordeste, e principal foco desse estudo, ilustrada no Gráfico 1. As receitas de produção, que correspondem às rendas das atividades de produção vegetal e animal e da agroindústria, são 2,8 vezes superiores na agricultura não familiar. Quando comparadas às outras receitas dos estabelecimentos, provenientes de atividades turísticas, artesanais, desinvestimentos, e outras não relacionadas com produção, ambos os sistemas apresentam valores próximos, $\mathrm{R} \$ 624$ milhões e R\$ 673 milhões, respectivamente, para os estabelecimentos não familiares e familiares. 


\section{Gráfico 1 - Receitas e outras rendas obtidas em estabelecimentos agropecuários no Nordeste, 2017}

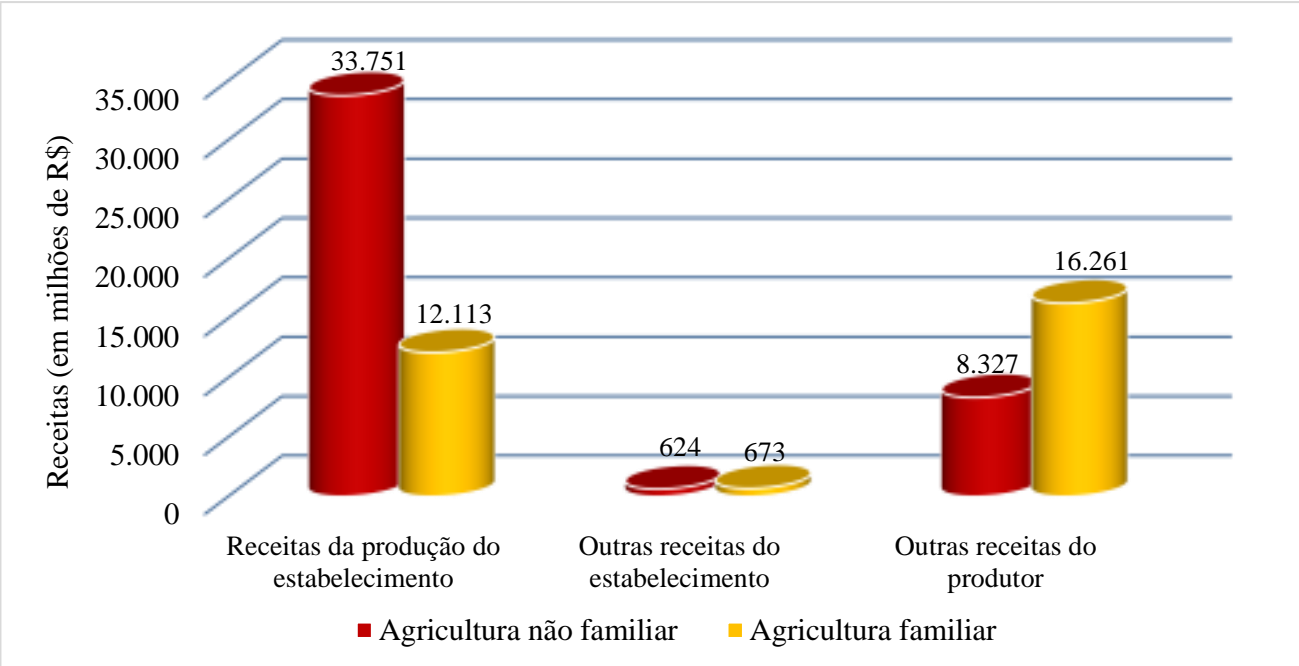

Fonte: Elaborado pelos autores a partir do Censo Agropecuário 2017 (IBGE, 2020).

O grupo das outras receitas do produtor rural é composto pelas rendas obtidas em atividades realizadas fora do estabelecimento agropecuário, provenientes de aposentadorias ou pensões, ou provenientes de programas governamentais, tais como o Programa Garantia Safra, Proagro, Programa Nacional de Habitação Rural Minha Casa Minha Vida, pagamento por serviços ambientais e outros programas. Esse grupo de rendas é duas vezes superior em estabelecimentos familiares, o que pode ser justificado pelo fato da agricultura familiar e pequenos produtores serem os principais públicos-alvo das políticas públicas voltadas ao meio rural. No entanto, o que chama a atenção é o fato das outras receitas do produtor familiar superarem suas receitas de produção, uma diferença superior a $R$ \$ 4,1 bilhões. Este comportamento repete em quase todos os estados da região Nordeste, com exceção do Maranhão, Sergipe e Rio Grande do Norte, e os valores quase se igualam no estado do Pernambuco.

As dessemelhanças entre os modelos familiar e não familiar, mais uma vez, ficam evidentes ao decompor o grupo de outras receitas do produtor rural. Além disso, destaca-se a importância dos programas governamentais e assistenciais na manutenção dos estabelecimentos familiares na região. As receitas obtidas fora do estabelecimento, aposentadorias e pensões e programas governamentais têm participações de 79,4\%,16,4\% e 4,2\%, respectivamente, no modelo de agricultura não familiar. Para a agricultura familiar, $84 \%$ das outras rendas são decorrentes de aposentadorias e pensões, 10,2\% são dos programas governamentais e 5,8\% de atividades externas ao estabelecimento rural. Estes 
resultados servem de indícios para analisar a dependência da agricultura familiar de fontes externas de renda, sobretudo dá margens para questionamentos sobre o papel de políticas públicas e programas governamentais para a subsistência de produtores familiares e sua influência sobre as atividades produtivas desenvolvidas nesses estabelecimentos.

De acordo com Bittencourt (2020), um dos grandes problemas dos estabelecimentos familiares refere-se ao tamanho da propriedade rural, que resulta em uma escala reduzida de produção e, consequentemente, é um dos fatores explicativos para a incidência de pobreza entre esse grupo. Exemplificando a região Nordeste, a autora destaca que " $72 \%$ dos produtores não geram lucro suficiente no estabelecimento para elevar a mão de obra familiar acima da linha da pobreza" (HELFAND et al., 2014 apud BITTENCOURT, 2020, p. 26).

Partindo desse contexto, a Figura 1 busca analisar a distribuição espacial das receitas entre os municípios do Nordeste. A figura ilustra a relação entre o valor das receitas totais e o número de estabelecimentos familiares e não familiares. Como receita total foi considerado o valor total apresentado pelo Censo Agropecuário 2017, este valor é diferente do somatório dos grupos de receitas (receitas de produção, receitas do estabelecimento e outras rendas do produtor). Pode-se observar que as regiões são coincidentes tanto para as de mais altas receitas relativas a cada tipo de produtores (familiares e não familiares) quanto para as de mais baixas receitas. Isso indica que as condições geográficas, climáticas e de solos são relevantes.

\section{Figura 1 - Distribuição das receitas médias por estabelecimentos agropecuários do}

\section{Nordeste, 2017}
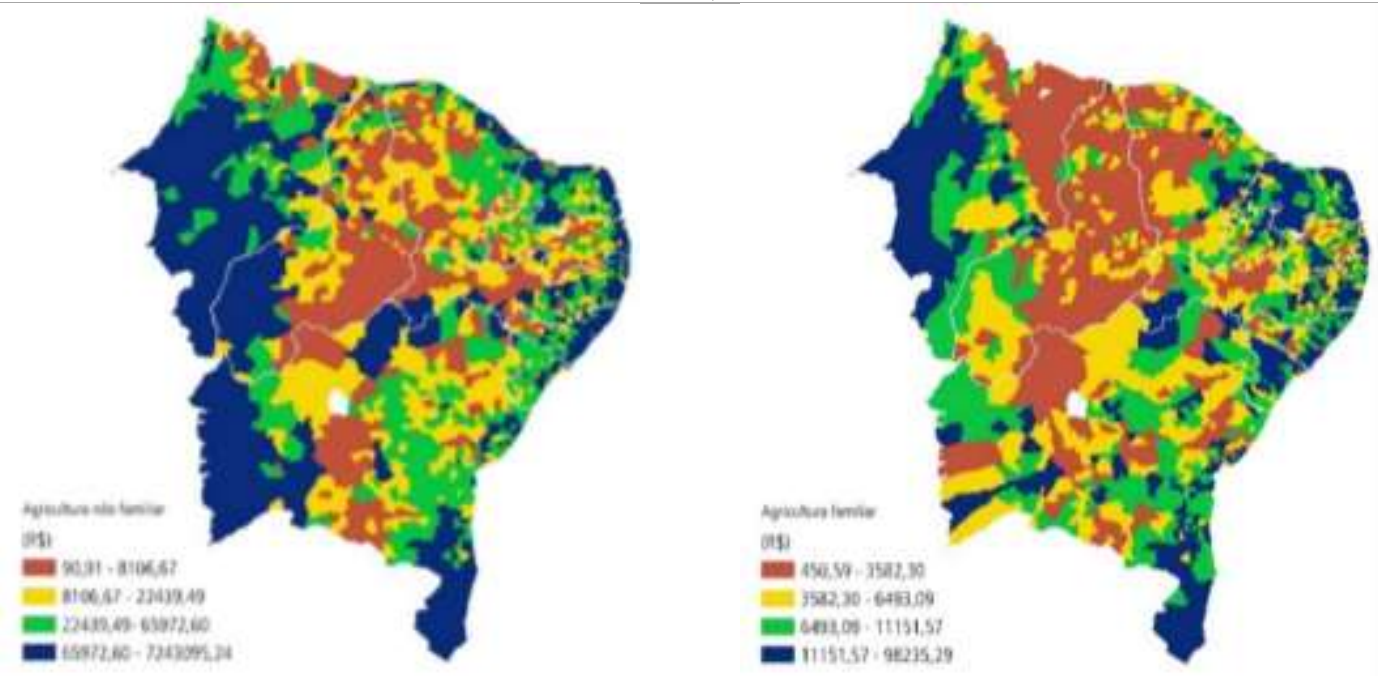

Fonte: Elaborado a partir de dados do Censo Agropecuário 2017 (IBGE, 2020). 
Observa-se uma grande discrepância entre as receitas médias municipais entre os estabelecimentos familiares e não familiares (Figura 1). No modelo não familiar, os valores variaram entre $\mathrm{R} \$ 90,91$ a $\mathrm{R} \$ 7.243 .095,24$ por estabelecimento. No modelo familiar, as variações encontram na faixa de $\mathrm{R} \$ 450,59$ a $\mathrm{R} \$$ 98.235,29, sendo que aproximadamente $18 \%$ dos municípios apresentaram receita média por estabelecimento abaixo de $\mathrm{R} \$ 3.000,00$. Estes resultados demonstram que as receitas dos estabelecimentos rurais seguem um padrão espacial de distribuição, uma vez que os melhores desempenhos são identificados ao longo das faixas litorâneas e na faixa Oeste da região, que engloba boa parte do estado do Maranhão e Oeste da Bahia. Por outro lado, as menores receitas coincidem com as áreas centrais da região Nordeste, que coincidem com a área de abrangência do Semiárido.

Para testar a hipótese de dependência espacial das receitas de estabelecimentos familiares no Nordeste, foi estimado o índice I de Moran para os três grupos de receitas: de produção, oriundas de outras atividades dos estabelecimentos e as fontes de rendas externas. Adicionalmente, dentro do grupo de rendas externas, considerou-se apenas as rendas provenientes dos programas governamentais para testar se a hipótese de dependência espacial também se aplica a esta categoria.

\section{Tabela 1 - Resultado da estimativa do índice I de Moran para grupos de receitas de} estabelecimentos familiares no Nordeste

\begin{tabular}{lc}
\hline \multicolumn{1}{c}{ Variável } & I de Moran \\
\hline Receitas de Produção (RPROD) & 0,341 \\
Receitas do Estabelecimento (REST) & 0,141 \\
Outras rendas do produtor (REXT) & 0,447 \\
Rendas de programas governamentais (RGOV) & 0,422 \\
\hline
\end{tabular}

Fonte: Resultado da pesquisa.

Conforme apresentado na Tabela 1, a estimação do índice de I de Moran apresentou valores mais próximos de zero e positivos, indicando a presença de uma baixa autocorrelação espacial entre os grupos de receitas dos estabelecimentos familiares do Nordeste. Entretanto, nota-se que a presença de autocorrelação é mais acentuada no grupo de outras rendas do produtor e particularmente na categoria de rendas provenientes de programas governamentais. 
Visando ilustrar os padrões de autocorrelação espacial, a Figura 2 apresenta um mapa de clusters LISA para cada grupo de receitas e rendas analisadas. O mapa apresenta dois tipos de clusters e dois tipos de outliers espaciais. Os clusters do tipo "Alto-Alto" englobam os municípios que apresentaram altos valores das receitas e estão cercados por municípios que também apresentaram receitas elevadas; na perspectiva contrária, os clusters do tipo "Baixo-Baixo" indicam os municípios que apresentaram menores receitas e estão rodeados por municípios com receitas também baixas. Os outliers representam áreas com comportamentos atípicos, assim os outliers do tipo "Alto-Baixo" são atribuídos a municípios com altas receitas mas rodeados por municípios com valores menores; enquanto os dos tipos "Baixo-Alto" são municípios com baixas receitas, cujos vizinhos apresentam valores elevados.

\section{Figura 2 - Clusters e outliers espaciais das receitas de estabelecimentos familiares do} Nordeste, 2017

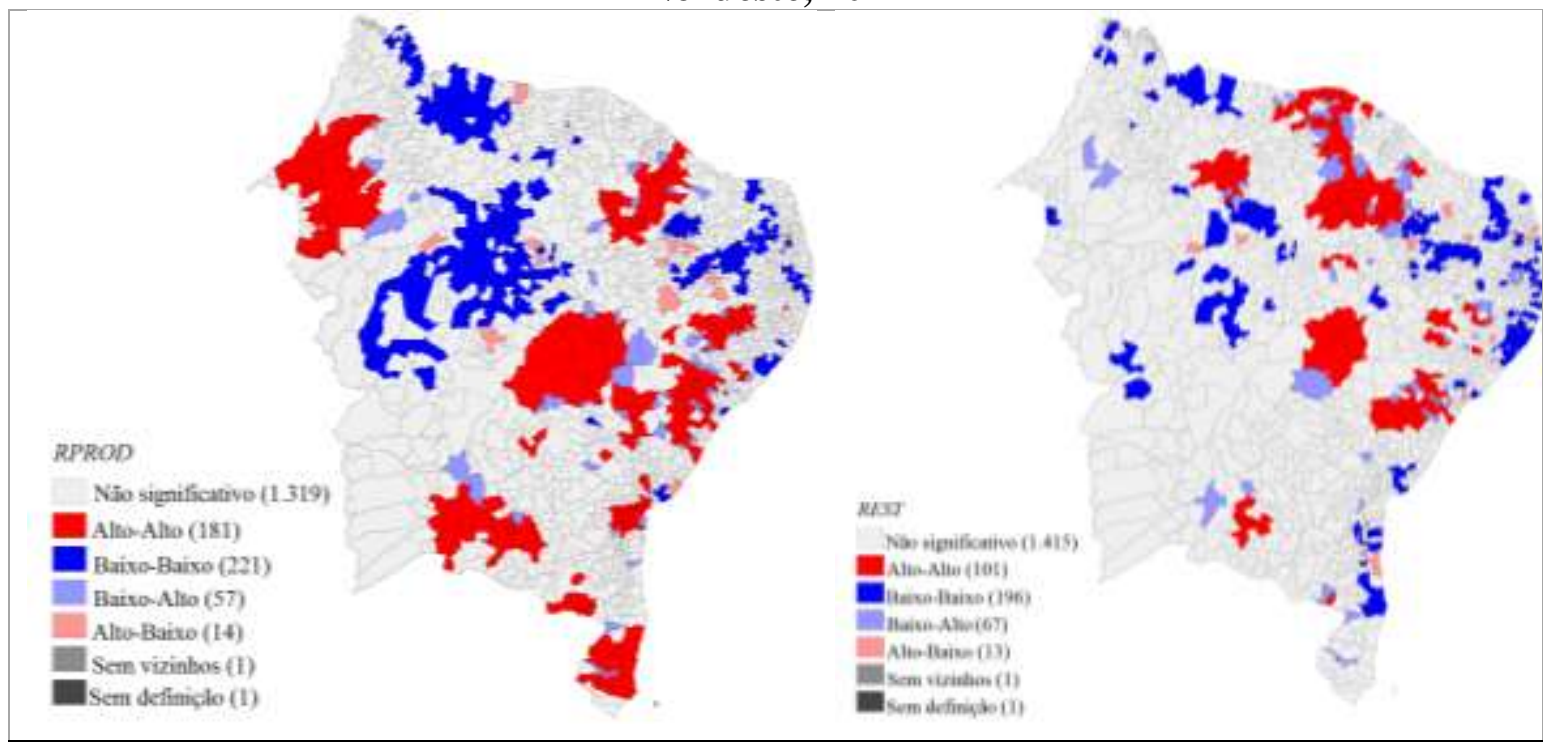




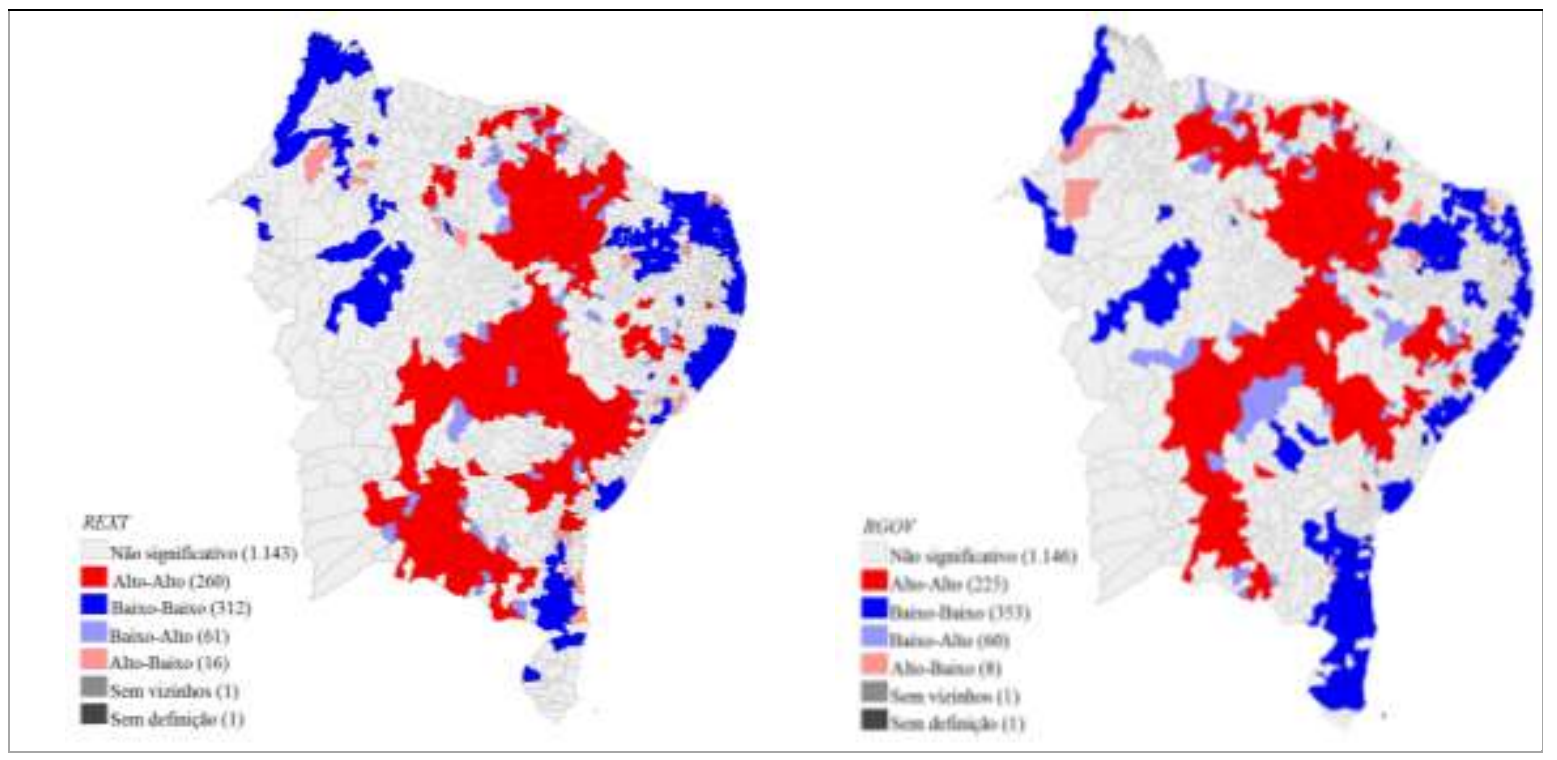

Fonte: Resultados da pesquisa.

Considerando as receitas de produção, percebe-se que 181 municípios pertencem ao cluster Alto-Alto, ou seja, formam áreas caracterizadas pelas altas receitas de produção dos estabelecimentos familiares. Observa-se que tais áreas estão localizadas em pontos específicos da região, com destaque para o centro-oeste maranhense, centro-sul baiano, na região são franciscana que abrange os estados da Bahia e Pernambuco, e em pequenas áreas localizadas no estado do Ceará e Alagoas. Por sua vez, os clusters do tipo Baixo-Baixo são mais visíveis no norte maranhense e em grande parte do estado do Piauí, totalizando 221 municípios.

Considerando as receitas dos estabelecimentos, conforme apresentado na Tabela 1, o índice I de Moran demonstrou uma fraca correlação espacial. Desta forma, apenas 101 municípios apresentação padrão Alto-Alto, sendo as maiores áreas localizadas no estado do Ceará e no norte da Bahia.

Acerca das outras fontes de renda do produtor, ou rendas externas, a análise espacial demonstrou um padrão mais detalhado do que nas duas análises anterior. Pode-se constatar que 260 municípios compõem o cluster Alto-Alto, que abrange uma faixa entre os estados do Ceará e a região centro-sul da Bahia. O padrão Baixo-Baixo engloba 312 municípios, dos quais a maioria estão localizados na faixa litorânea do Nordeste e no norte maranhense e oeste piauiense. Ao insolar apenas as receitas provenientes de programas governamentais, neste caso excluindo as receitas de aposentadorias e as obtidas fora do estabelecimento 
familiar, o padrão espacial se repete, indicando a dependência espacial dessa categoria de receitas nas áreas citadas.

Em síntese, observa-se que o comportamento das receitas é resultante não de questões espaciais, mas da alocação dos fatores, da estrutura produtiva, tecnologia, entre outros. A análise espacial torna perceptível a dependência das receitas externas e de programas governamentais na região semiárida. Devido às condições edafoclimáticas dessa região, longos períodos de secas, escassez hídricas e degradação os solos e o uso de práticas tradicionais, ou seja, com baixos incrementos tecnológicos, a produtividade e consequentemente as receitas de produção ficam comprometidas. As desigualdades socioeconômicas é um outro fator característico desta região, assim grande parte dos produtores familiares encontram-se em situação de vulnerabilidade, em condições de pobreza ou extrema pobreza. Essa realidade justifica os repasses de programas governamentais, e também justifica as receitas externas superarem as receitas de produção, conforme apresentados anteriormente no Gráfico 1.

Cerca de 90,2\% dos estabelecimentos agropecuários familiares possuem áreas de até 50 hectares, outros 2,3\% são classificados como produtores sem área. De acordo com a Lei da Agricultura Familiar (Lei no 11.326/2006), são classificados como estabelecimentos familiares aqueles cuja área total não ultrapassa quatro módulos fiscais. Assim, como cada município apresenta sua própria dimensão do módulo fiscal, o tamanho dos estabelecimentos podem apresentar grandes variações de um estado para outro.

Fazendo uma análise da distribuição percentual, 72,1\% e 61,5\% das receitas de produção e de outras atividades realizadas nos estabelecimentos, respectivamente, então concentradas nos grupos com área superior a 5 hectares. Por outro lado, as receitas externas e as receitas governamentais se concentram entre o grupo de produtores sem área ou com até menos de 10 hectares, em valores percentuais iguais a $61,0 \%$ e $75,0 \%$, respectivamente. 


\section{Gráfico 2 - Distribuição das receitas de estabelecimentos familiares por grupos de área total no Nordeste, 2017}

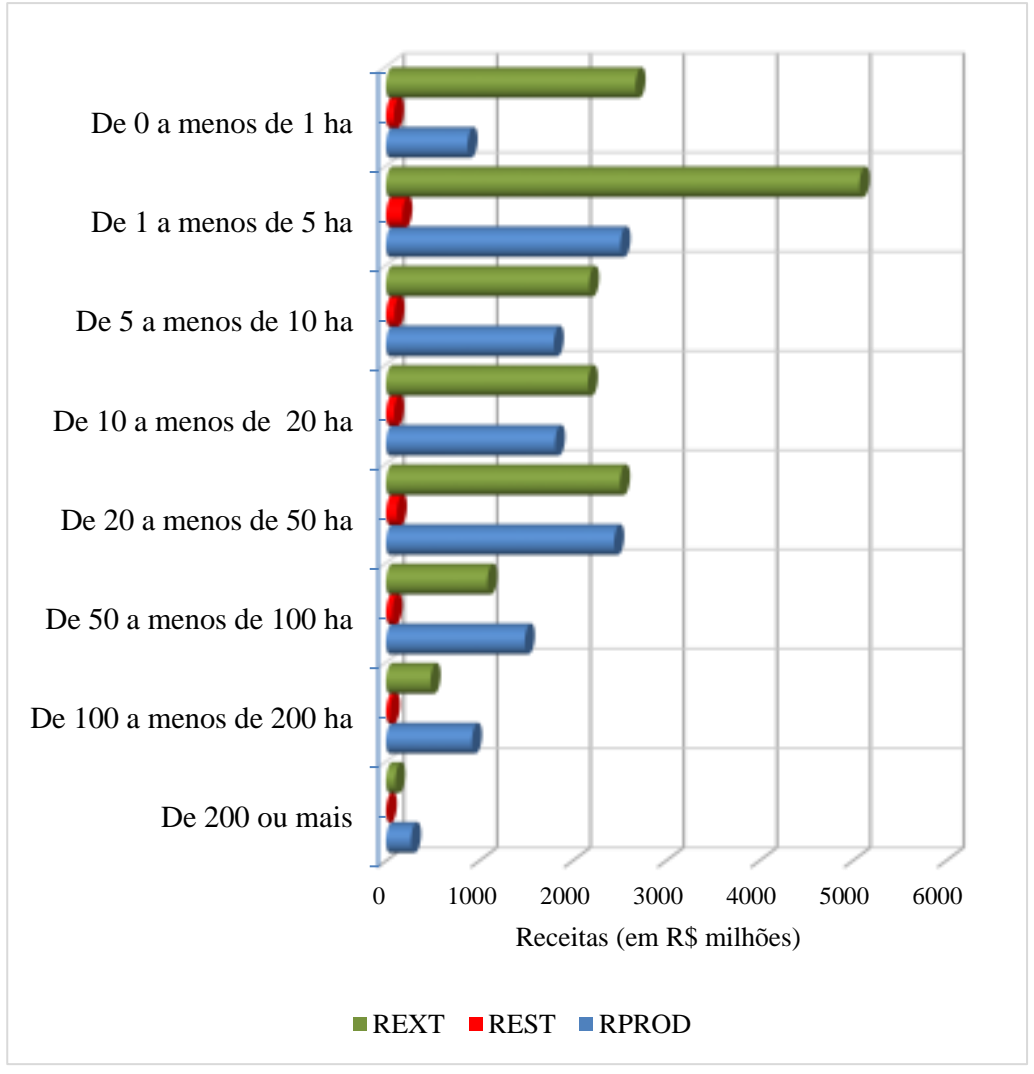

Fonte: Elaborado pelos autores a partir do Censo Agropecuário 2017 (IBGE, 2020).

Nesse contexto, e confrontando os dados apresentados no Gráfico 2, observa-se que as receitas externas superam as receitas de produção nos grupos de área de até 50 hectares. A partir de 50 hectares, as receitas de produção superam as receitas externas, demonstrando que o tamanho da escala de produção exerce influência no comportamento das receitas dos estabelecimentos familiares. Além disso, esse comportamento deve-se ao fato de os pequenos produtores rurais serem o público alvo de políticas governamentais, recebendo os repasses financeiros oriundos de tais programas, a exemplo do Programa Garantia Safra e do Programa de Garantia da Atividade Agropecuária da Agricultura Familiar (Proagro Mais), e serem dependentes de pensões e aposentadorias e de outros programas governamentais, a exemplo do Programa Bolsa Família, em decorrências da alta vulnerabilidade socioeconômica desse grupo.

A vulnerabilidade da agricultura familiar no Nordeste é agravada por fatores estruturais, como o limitado acesso à terra e aos ativos produtivos, à assistência técnica e meios de comercializar a produção, conforme apresentado na Introdução. Tais características 
resultam em heterogeneidade produtiva, resultado da concentração de renda e ativos. Os dados apontam que em $78 \%$ dos estabelecimentos familiares o produtor é proprietário das terras; apenas $79 \%$ dos estabelecimentos têm acesso à energia elétrica; outros $9 \%$ fazem uso de algum método de irrigação; 7\% recebem orientação técnica e 13\% obtiveram financiamentos (IBGE, 2020). Fatores sociais também são relevantes para caracterizar o modelo familiar na região. A participação feminina, por exemplo, representa $24 \%$ da direção dos estabelecimentos familiares e $32 \%$ do pessoal ocupado; $49 \%$ dos produtores têm entre 55 anos ou mais; $26 \%$ nunca frequentaram a escola e pouco mais de $1 \%$ possuem ensino superior (IBGE, 2020).

\section{CONSIDERAÇõES FINAIS}

A agricultura familiar é responsável por grande parte da produção dos alimentos que chegam até as mesas das famílias brasileiras. Diferente da agricultura patronal e dos grandes latifundiários, os pequenos produtores e o sistema de produção familiar estão altamente vulneráveis aos problemas ambientais, à competitividade dos mercados, à aspectos socioeconômicos, à limitada escala de produção, ao restrito acesso a recursos e crédito, falta de infraestrutura e baixos níveis tecnológicos, entre outros fatores. Considerando a vasta extensão do território brasileiro, a agricultura familiar se comporta de maneiras diferentes entre os estados e regiões, existindo áreas com uma agricultura familiar mais desenvolvida e rentável do que outras. Muitos desses problemas são observados na região Nordeste, o que justificar o interesse por essa área de estudo.

A abordagem descritiva e comparativa das receitas de estabelecimentos familiares e não familiares no Nordeste demonstrou que financeiramente esses dois sistemas são desiguais, como destaca a magnitude das variações entre as receitas totais máximas e mínimas observadas nos dois modelos, e apresentadas nesse estudo. Entender como se comporta as receitas e rendas também demonstra que esses grupos apresentam necessidades distintas relacionadas tanto à sua relação com as atividades produtivas quanto às suas necessidades de subsistência. Os resultados permitiram, também, comparar a influência do tamanho dos estabelecimentos familiares sobre o comportamento das receitas, de modo a identificar que os menores grupos de área total dependem de rendas externas provenientes 
dos programas governamentais. Na medida em que se ampliam a área da propriedade, os ganhos com a produção se elevam.

Portanto, há relação direta entre os maiores patamares de receita e área (e pressuposta renda líquida por área cultivada em maior volume, mantidas as demais condições). Este é um elemento estrutural que resulta em heterogeneidades produtivas, como se observou. Há de se considerar também os auxílios do governo para a manutenção dos estabelecimentos de pequeno porte no Nordeste (propriedades menores de cinco hectares, principalmente) e os produtores sem terra, bem como a sua brava resiliência e os seus esforços de se manterem no campo, possivelmente pelo fato de as condições de vida nas cidades não serem mais vantajosas. Assim, a mensagem clara que deve ser ressaltada é que os ativos são determinantes dos atrasos, das desigualdades e da heterogeneidade produtiva.

Portanto, mostraram-se equivocadas ou insuficientes as políticas e escolhas de ações que não efetivaram as condições mínimas de acesso à terra em maior quantidade aos produtores resilientes demandantes desse ativo e de políticas públicas de apoio à produção e comercialização. Dessa forma, a efetivação do acesso à terra (seja por meio de reforma agrária, assentamentos aprimorados, propriedade coletivas, ocupação de terras por projetos familiares, etc.) e às condições estruturantes da produção fazem sentido ainda no Brasil. Caso contrário, a dependência externa e a perda de potenciais tendem a permanecer, sendo ilusórias as medidas paliativas. É sabido, contudo, que acordos nesse sentido, tornando a agricultura familiar mais dinâmica e menos dependente de renda externa à produção, somente ocorrerá em um cenário de reconhecimento de direitos e havendo demanda e organização social que levem tais bandeiras a governos democráticos.

A utilização de ferramentas de análise espacial forneceram bons subsídios para entender a dinâmica da agricultura familiar no Nordeste. Apesar da estimação do índice I de Moran ter demonstrado uma fraca correlação espacial, sua aplicação foi efetiva para identificar diferentes comportamentos dos estabelecimentos familiares em relação às receitas. Em síntese, a análise espacial demonstrou os contrastes na agricultura familiar desenvolvida na faixa litorânea (Zona da Mata) e em grande parte do território maranhense (área de biomas amazônico e cerrado) dos demais modelos familiares desenvolvidos no sertão nordestino, em outras palavras, as duas primeiras áreas apresentam um melhor desempenho em relação às receitas do que no interior do Nordeste. 
O entendimento das particularidades apresentadas pela agricultura familiar na região Nordeste é importante para a caracterização e o reconhecimento das fragilidades dos pequenos produtores de modo a orientar a reformulação de políticas públicas e programas específicos destinados a este grupo. Os resultados desta pesquisa indicaram que a agricultura familiar no Nordeste, principalmente entre os estabelecimentos localizados na região semiárida, além da distribuição de renda, é necessário criar maior abertura para o pequeno e médio produtor rural a ativos essenciais para a produção, como maior área e acesso ao sistema de crédito, de forma a garantir as manutenção das atividades produtivas.

Como sugestões para pesquisas futuras destaca-se a importância de investigar a fundo o comportamento da agricultura familiar por meio dos microdados do Censo Agropecuário 2017. Eles possibilitarão uma visão mais detalhada dos estabelecimentos, de forma a ampliar as análises em um contexto mais próximo da realidade, uma vez que a escala municipal não permite maiores aprofundamentos. É também importante ampliar o estudo para outras regiões brasileiras, visto que a agricultura familiar é representativa em todo o país, com características e heterogeneidades que merecem ser estudadas.

\section{REFERÊNCIAS}

ANSELIN, L. Local Indicators of Spatial Association - LISA. Geographical Analysis, v. 27, n. 2, p. 93-115, april 1995.

BAIARDI, A.; ALENCAR, C. M. M. Agricultura familiar, seu interesse acadêmico, sua lógica constitutiva e sua resiliência no Brasil. Revista de Economia e Sociologia Rural, Brasília, DF, v. 52, supl. 1, p. 45-62, 2014.

BELIK, W. A heterogeneidade e suas implicações para as políticas públicas no rural brasileiro. Revista de Economia e Sociologia Rural, Piracicaba, SP, v. 53, n. 1, p. 9-30, jan./mar. 2015.

BITTENCOURT, D. M. C. Agricultura familiar, desafios e oportunidades rumo à inovação. In: BITTENCOURT, D. M. C. (Ed.). Estratégias para a Agricultura Familiar: visão de futuro rumo à inovação. Brasília, DF: Embrapa. 2020. p. 23-34. (Texto para Discussão 49). BRASIL. Lei n ${ }^{\circ} 11.326$, de 24 de julho de 2006. Estabelece as diretrizes para a formulação da Política Nacional da Agricultura Familiar e Empreendimentos Familiares Rurais. Diário Oficial da União, Brasília, DF, 25 jul. 2006. 
Lei $\mathrm{n}^{\circ}$ 12.512, de 14 de outubro de 2011. Institui o Programa de Apoio à

Conservação Ambiental e o Programa de Fomento às Atividades Produtivas Rurais; altera as Leis $n^{\circ}$ s 10.696, de 2 de julho de 2003, 10.836, de 9 de janeiro de 2004, e 11.326, de 24 de julho de 2006. Diário Oficial da União, Brasília, DF, 17 out. 2011.

Decreto $n^{\circ}$ 9.064, de 31 de maio de 2017. Dispõe sobre a Unidade Familiar de Produção Agrária, institui o Cadastro Nacional da Agricultura Familiar e regulamenta a Lei $\mathrm{n}^{\mathrm{o}} 11.326$, de 24 de julho de 2006, que estabelece as diretrizes para a formulação da Política Nacional da Agricultura Familiar e empreendimentos familiares rurais. Diário Oficial da União, Brasília, DF, Edição extra, 31 maio 2017.

CÂMARA, G.; CARVALHO, M. S.; CRUZ, O. G.; CORREA, V. Análise espacial de áreas. In: DRUCK, S. et al. (Ed.). Análise Espacial de Dados Geográficos. Brasília: EMBRAPA, 2004. cap. 5.

CAPORAL, F. R.; COSTABEBER, J. A. Agroecologia e Extensão Rural: Contribuições para a Promoção do Desenvolvimento Rural Sustentável. Porto Alegre: IICA, 2004. 177 p. CASTRO, C. N. A agricultura no Nordeste brasileiro: oportunidades e limitações ao desenvolvimento. Brasília: Ipea, 2012. (Texto para Discussão, n. 1786).

. Desafios da agricultura familiar: o caso da assistência técnica e extensão rural.

Boletim Regional, Urbano e Ambiental, Brasília, DF, n. 12, p. 49-59, jul./dez., 2015. DEL GROSSI, M. E. Algoritmo para delimitação da agricultura familiar no Censo Agropecuário 2017, visando a inclusão de variável no banco de dados do Censo, disponível para ampla consulta. Brasília: FAO/Finatec-UnB/Mapa, 2019. 25 p. DEL GROSSI, M. E.; FLORIDO, A. C. S; RODRIGUES, L. F. P. Agricultura Familiar no Censo Agropecuário: principais causas de exclusão da agricultura familiar nos algoritmos. Versão de 8 de novembro de 2019.

FRANÇA, C. G.; GROSSI, M. E. D.; MARQUES, V. P. M. A. O Censo Agropecuário 2006 e a agricultura familiar no Brasil. Brasília: MDA, 2009. 96 p.

FREIRE, J. A. Política agrícola e sustentabilidade da agricultura familiar no Nordeste brasileiro: anos 90. Raízes, ano XVIII, n. 20, p. 76-89, nov., 1999.

GUANZIROLI, C. E.; DI SABBATO, A.; VIDAL, M. F. Evolução da agricultura familiar nordestina: uma análise comparativa entre os dois censos agropecuários. Revista Econômica do Nordeste, Fortaleza, v. 45, suplemento especial, p. 93-105, out./dez., 2014. 
IBGE - INSTITUTO BRASILEIRO DE GEOGRÁFIA E ESTATÍSTICA. Censo

Agropecuário 2017: Resultados definitivos. Disponível em:

<https://sidra.ibge.gov.br/pesquisa/censo-agropecuario/censo-agropecuario-2017>. Acesso em: 23 de março de 2020.

LIMA, J. R.; MAGALHÃES, A. R. Secas no Nordeste: registros históricos das catástrofes econômicas e humanas do século 16 ao século 21. Parcerias Estratégicas, v. 23, n. 46, p. 191-212, jan./jun. 2018.

LUZARDO, A. J. R.; CASTAÑEDA FILHO, R. M.; RUBIM, I. B. Análise espacial exploratória com o emprego do Índice de Moran. GEOgrafia, Niterói, v. 19, n. 40, p. 163 179, 2017.

MEDEIROS, C. M. Industrialização e agricultura: o complexo agroindustrial do arroz em Santa Catarina. Cascavel: Edunioeste, 2006. 189 p.

NETTO, M. M. A agricultura familiar e sua organização. Revista Acta Geográfica, ano 2, n. 4, p.17-30, jul./dez., 2008.

PICOLOTTO, E. L. Os atores da construção da categoria agricultura familiar no Brasil.

Revista de Economia e Sociologia Rural, Brasília, DF, v. 52, supl. 1, p. 63-84, 2014.

SABOURIN, E. Origens, evolução e institucionalização da política de agricultura familiar no Brasil In: DELGADO, G. C.; BERGAMASCO, S. M. P. P. (Org.). Agricultura

familiar brasileira: desafios e perspectivas de futuro. Brasília: Ministério do

Desenvolvimento Agrário, 2017. p. 265-291.

SAMBUICHI, R. H. A. et al. (Org.). Política Nacional de Agroecologia e Produção

Orgânica no Brasil. Brasília: Ipea, 2017.

SANTANA, A. S.; SANTOS, G. R. Impactos da seca de 2012-2017 na região semiárida do Nordeste: notas sobre a abordagem de dados quantitativos e conclusões qualitativas.

Boletim Regional, Urbano e Ambiental (IPEA), Brasília, DF, v. 22, p. 119-129, 2020. SCHNEIDER, S. CASSOL, A. A agricultura familiar no Brasil. Santiago (CL): RIMIST, set. 2013. (Serie Documentos de Trabajo, n. 145).

Diversidade e heterogeneidade da agricultura familiar no Brasil e algumas implicações para políticas Públicas. In: DELGADO, G. C.; BERGAMASCO, S. M. P. P. (Org.). Agricultura familiar brasileira: desafios e perspectivas de futuro. Brasília: Ministério do Desenvolvimento Agrário, 2017. p. 82-109. 